\title{
Consequences of 660 nm Diode Laser Following Postsurgical Exodontia in Patients under Contraceptive Pills: A Randomized Double-blinded Clinical Trial
}

\author{
Suzan Salem
}

\begin{abstract}
Aim: The photobiomodulation (PBM) effect of $660 \mathrm{~nm}$ diode laser in reducing pain, edema, trismus and promote healing subsequently to the transalveolar extraction of mandibular third molars in female patients taking contraceptive pills were evaluated.

Materials and methods: Fifty female patients participated in our study. The $660 \mathrm{~nm}$ diode laser was applied immediately on randomly selected patients of the study group $(n=25)$ over the surgical site for 1 minute with continuous laser beam application. For the control group $(n=25)$, the same extraction procedure was performed without the application of $660 \mathrm{~nm}$ diode laser. Pain intensity, swelling, trismus, and healing was evaluated before extraction and during recall visits 24 hours, 48 hours, and 7 days postoperatively.

Results: The values of pain, swelling, and trismus were significantly inferior in the study group compared to the control group ( $p<0.05)$ at $\mathrm{T} 2$ and T3; while the values of the healing index were significantly superior in the study group compared to the control $\operatorname{group}(p<0.001)$ at T1, T2, and T3. Conclusion: Using $660 \mathrm{~nm}$ diode laser reduced the postsurgical discomforts (pain, edema, and trismus) and promote healing associated following transalveolar extraction of the lower third molar.

Clinical significance: To develop a framework based on the results regarding the PBM effect of $660 \mathrm{~nm}$ diode laser following transalveolar extraction of lower third molar in a female patient taking oral contraceptive pills, which may help to improve the treatment services provided to the community.

Keywords: Contraceptive pills, Photobiomodulation, $660 \mathrm{~nm}$ diode laser, Transalveolar extraction.

The Journal of Contemporary Dental Practice (2020): 10.5005/jp-journals-10024-2736
\end{abstract}

\section{INTRODUCTION}

Third molar extraction surgery is one of the standard procedures in oral surgery and is known as a standout amongst the most well-known measure performed in maxillofacial outpatient procedures. $^{1-3}$ It is frequently accompanied with postoperative complications that usually presented with various frequencies and a broad extent of features, extends from slight postoperative discomfort to progressively complexities that necessitate further management with the capability of changeless harm to healing. ${ }^{4}$

Transalveolar extraction frequently accompanied by postoperative pain, swelling, and trismus which reaches its peak postsurgical within the first 5 hours and lasted for 2-3 days and start to subside slowly till the 7th day postoperatively. ${ }^{5,6}$ Moreover, post-surgical edema has high incidence to develop and usually originated from tissue responses to surgical manipulation. Its onset is slow and reaches to its peak after 48 hours postoperatively. ${ }^{7}$ Edema starts to subside at the 4th postoperative day and totally disappear at the 7 th postoperative day. ${ }^{8}$

Jaw stiffness also had been that rise and reaches its peak on the 2nd postsurgical day and completely disappears within 1 week. ${ }^{9}$ There is a direct relation between postoperative pain and limitation of mouth opening, supposing that pain might be one of the principle reasons to develop trismus following transalveolar extraction procedures. ${ }^{9}$ Edema, pain, and trismus are reckoned as temporary adverse symptoms that may develop after surgery. Although these complications are temporary they may cause anxiety for the patient. ${ }^{8}$

On some occasions, the succession of typical healing after extraction does not generally, take place, an early blood clot
Department of Oral Surgery, Maxillofacial and Diagnostic Science, College of Dentistry, Qassim University, Buraydah, Al Qassim, Kingdom of Saudi Arabia

Corresponding Author: Suzan Salem, Department of Oral Surgery, Maxillofacial and Diagnostic Science, College of Dentistry, Qassim University, Buraydah, Al Qassim, Kingdom of Saudi Arabia, Phone: +966 531017409, e-mail: Dr.suzan.salem@qudent.org

How to cite this article: Salem S. Consequences of $660 \mathrm{~nm}$ Diode Laser Following Postsurgical Exodontia in Patients under Contraceptive Pills: A Randomized Double-blinded Clinical Trial. J Contemp Dent Pract 2020;21(1):2-10.

Source of support: This research was self-funding, the researcher would like to Acknowledge, College of Dentistry, Qassim University for its support in conduction this study

Conflict of interest: None

may be formed within the extraction socket and followed by premature fibrinolysis of the clot, associated with pain, halitosis, ${ }^{10}$ and development of alveolar osteitis (AO) that usually appears at the third postextraction day. ${ }^{9}$

The oral contraceptive pill is one of the main drugs that was connected to the development of AO. It used widely since 1960s and several studies report a significantly higher rate of $A O$ in females taking oral contraceptive pills. ${ }^{11-13}$ Estrogen was assumed to significantly cause effect on the fibrinolytic cycle. Estrogen indirectly will stimulate the fibrinolytic cycle (elevating factors II, VII, $\mathrm{VIII}, \mathrm{X}$, and plasminogen) and consequently escalates disintegration of the fibrin clot and increasing the possibility of developing $\mathrm{AO} .^{14}$ 
Different strategies had been proposed for controlling the immediate inflammatory reactions that might be developed following the transalveolar extraction of the lower third molar in the literature. Some proposed various surgical closure approaches with or without using drains, ${ }^{15,16}$ using medication such as analgesics, ${ }^{17}$ corticosteroids, ${ }^{18,19}$ fibrin and platelet glue, ${ }^{20,21}$ antibiotics ${ }^{22,23}$ and other proposed new modalities to include physical therapeutic approaches such as cryotherapy ${ }^{24}$ and laser application. ${ }^{25}$

The implementation of low-level laser therapy (LLLT) as a successful tool in dentistry reported in the literature for more than three decades. ${ }^{26}$ Photobiomodulation, likewise known also as LLLT uses the energy of light to initiate biological reactions from the cell and organize the cell function. Several investigations reported that LLLT acts on the mitochondria of the cell, primarily on cytochrome C oxidase enzyme in the electron transfer chain and porphyrins on the cell membrane. ${ }^{26,27}$

Using PBM postsurgically aimed to reduce the need for analgesics postoperatively and accelerating patient recovery immediately after surgery which effects on patient feedback toward their dental treatment. ${ }^{28}$

Several studies have exhibited that PMB can significantly reduce pain throughout the healing period, also encourage soft tissue healing, making it a promising treatment tool after surgical procedures. ${ }^{29,30}$

Low-level laser therapy show more superior results than other modalities and, contingent on the dosage, wavelength, and the context of the irradiated area, it can enhance a wide cellular reaction. Also, it had been utilized with different power densities to reduce tissue damage. Laser energy proved to improve the proliferation of osteoblasts, epithelial cells and fibroblasts, activation of the lymphatic system, increased angiogenesis, and bone mineralization. ${ }^{5}$

Furthermore, some investigators reported the improvement of the ingestion of proteins by enhancing macrophages activity and improving intracapillary hydrostatic pressure that decrease the extracellular fluid, reducing postsurgical edema. ${ }^{31,32}$

In addition, LLLT has been proved to significantly reduce inflammation through its antiinflammatory action on the initial healing stages; lowering chemical mediators, cytokines, swelling, and migration of inflammatory cells, and enhance growth factors synthesis, which directly play an important role in the tissue recovery process, in addition to its indirect action on the reduction of the inflammation inherent that will boost the repair of the daily damage of tissues. ${ }^{33}$

Many investigations proposed also that LLLT has a pain relieving impact as it provides a better-balanced arrangement of the lipid bilayers providing more stabilization of nerve cell membranes, also augment the oxidation-reduction status of the cells and would stimulate the formation of adenosine triphosphate (ATP), promoting the rebuilding of neuronal membranes and reducing transmission of pain. ${ }^{34,35}$

Several limitations of using laser therapy had been reported and were attributed to its possible biostimulation response on benign and malignant cells. The chance of irradiating the gonads, threatening of eye and thyroid gland irradiation, cardiac pacemaker, epilepsy, pregnancy, local infection, hematological disease patients with a malignant tumor and photosensitive skin or use of medication that causes photosensitivity considered as a contraindication for the use of laser therapy. ${ }^{36,37}$

To date, there is no report in the English language, literature light on the effect of LLLT in decreasing the possibility of postoperative complication that may be developed following transalveolar extraction of lower third molars in the female patient taking oral contraceptive pills. The current study will attempt to throw light on the PBM effect of LLLT which increases the perception of the patients toward the dental services provided to them.

\section{Materials and Methods}

\section{Subjects}

Fifty female adult patients with a clinical and radiographically hopeless mandibular third molar indicating for extraction were selected from the outpatient dental clinic of the College of Dentistry, Qassim University. Consents were obtained from all participants after providing detailed information about the laser therapy, its uses, impacts, indications, and expected reactions.

\section{Subjects Inclusion/Exclusion Criteria}

The following criteria had been applied in selecting patients participating in this study.

\section{Inclusion Criteria}

- Age range from 30 to 45 years with mean 32.3 years.

- All participants were grade I according to American Society of Anesthesiologists (ASA).

- Patients taking oral contraceptive pills.

- Normal hematological values.

\section{Exclusion Criteria}

- Patients with ASA grades II, III, and IV.

- Patients with extraoral swelling and cellulitis.

- Patients with temporomandibular joint ankyloses.

- Patients with systemic diseases.

- Local infection related to the lower third mandibular teeth.

- Patients were on antibiotics or analgesics treatment for the last month before extraction.

\section{Study Design}

The research was a randomized, double-blinded, controlled clinical trial conducted on female patients following transalveolar extraction of the mandibular third molar. Participants were randomly divided into two groups, the study group $(n=25)$ received $660 \mathrm{~nm}$ diode laser $(n=25)$ and the control group $(n=25)$ who did not receive diode laser. All surgical procedures were performed by the same investigator; while the assessment was performed by a different one.

\section{Pretreatment Assessment}

History

A detailed patient history was obtained from the selected patients including name, age, medical and medication history.

\section{Treatment Protocol}

All surgical procedures were carried out after effectively anesthetized the region of concern using inferior alveolar nerve block and long buccal nerve block techniques with OCTOCAINE 100 "Lidocaine $\mathrm{HCl}$ and 2\% and Epinephrine 1:100,000" (Novocol Pharmaceutical of Canada, Inc., Ontario, Canada).

The difficulty of the surgical procedures was evaluated postoperatively using the parent scale modified by Garcia Garcia et al. $^{38}$ (Table 1$)$. 
Table 1: Parent surgical difficulty scale modified by Garcia Garcia

\begin{tabular}{ll}
\hline Type & Technique \\
\hline I & Simple extraction \\
II & Extraction requiring ostectomy \\
III & Extraction requiring ostectomy and coronal \\
& section \\
IV & Complex extraction (root section) \\
\hline
\end{tabular}

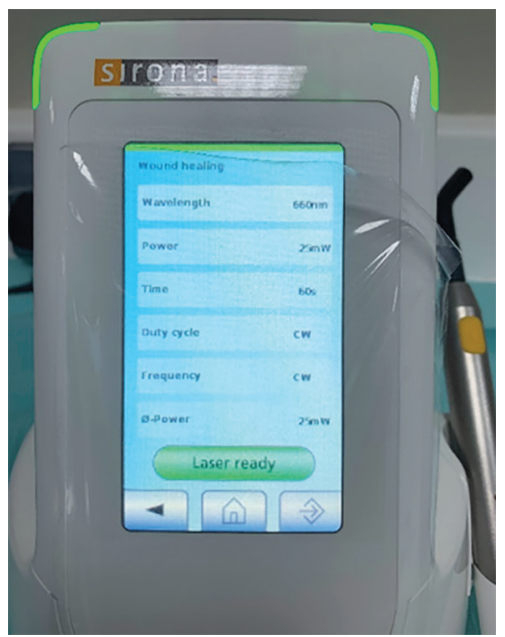

Fig. 1: SIRO laser $660 \mathrm{~nm}$

A LLLT (SIRO Laser, Sirona Dental Systems GmbH, Bensheim, Germany Fig. 1) was utilized in the investigation. All participants were not informed if they had received laser therapy or not. In the study group, the laser intensity was adjusted $25 \mathrm{~mW}$, with a wavelength of $660 \mathrm{~nm}$. The diode laser MultiTip (SIRO Laser, Sirona Dental Systems GmbH, Bensheim, Germany) was used in noncontact mode and was set at a distance of $1 \mathrm{~cm}$ from the tissue surface. The laser device was activated and the diode red light was applied with constant laser beam illumination for 60 seconds over the surgical area (Fig. 2). In the control group, the diode laser MultiTip was placed over the surgical area, but without any illumination.

Normal saline mouth wash had been prescribed for all participants and the sutures were removed on the 7 th day postoperatively.

Postoperative instructions, including soft dietary intake on the first 48 hours after surgery, and no tooth brushing, rinsing or spitting on the day of surgery. Also, they were advised to start regular tooth brushing on the second day after surgical procedure, taking into consideration to avoid tooth brushing near the site of surgical for 72 hours.

\section{Treatment Sequence}

Before starting the procedures (baseline; T0) and during recall visit, (24 hours postsurgical; T1, 48 hours postsurgical; T2, and 7 days postsurgical; T3) a schedule was followed. The reasons for this schedule were to achieve patient compliance and to achieve effective numbers of application of the treatment. The application of diode laser, evaluating posttreatment results, and collecting data were carried out by different examiner.

\section{Posttreatment Evaluation}

Subjective and objective assessments were recorded for each patient.

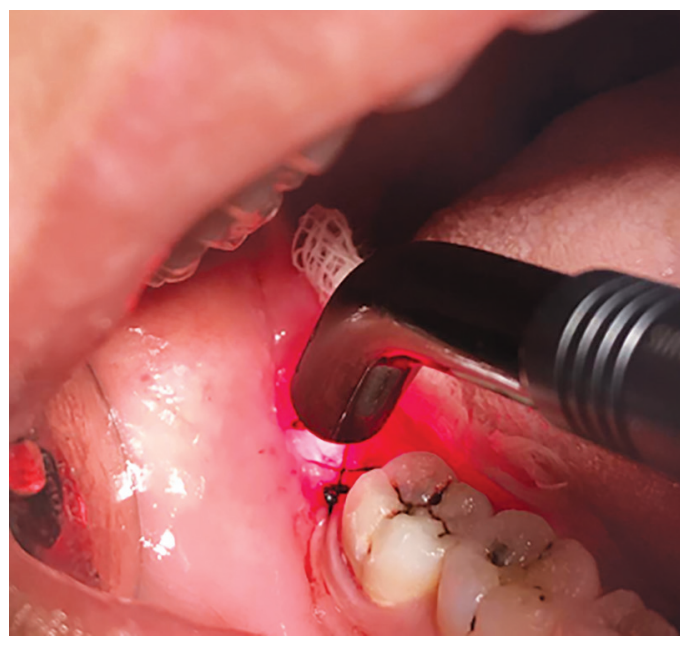

Fig. 2: SIRO laser $660 \mathrm{~nm}$ in use

\section{Subjective Evaluation}

Universal pain assessment tool (UPAT) had been used for subjective evaluation (Fig. 3). Using UPAT assess the level of pain using faces or behavioral expressions to interpret pain if patients are unable to identify the severity of their pain. It consisted of a $10 \mathrm{~cm}$ printed chart marked from 0 to 10 (0; no pain, 1-3; minor pain experienced, 4-6; moderate pain experienced and 7-10; severe pain experienced) and was measured at four points of the treatment sequence. ${ }^{39}$

\section{Objective Evaluation}

The postsurgical edema was measured immediately after 24 hours of the surgical procedure (the baseline level was set before surgery). The distance from the chin tip to the lower part of the auricle lobe was measured at four points of the treatment sequence, and the edema coefficient $\left(E_{c}\right)$ was calculated using the modified equation of Carrillo. ${ }^{40}$

$$
E_{c}=\frac{\text { postoperative distance }- \text { preoperative distance }}{\text { preoperative distance }} \times 100
$$

Limitation of mouth opening or trismus was evaluated at the four points of the treatment sequence by measuring the maximum interincisal opening with a ruler. ${ }^{40}$ Participants who have a $10 \mathrm{~mm}$ at $\mathrm{T} 2$ and $\mathrm{T} 3$ should be considered with trismus. ${ }^{41}$

The wound and soft tissue healing evaluation was performed using the Landry and Turnbull index ${ }^{42}$ (Table 2).

\section{Statistical Analysis}

The results were statistically analyzed using the Statistical Package for Social Sciences (SPSS for Windows, release 17 Chicago, IL). The statistical test used as follows:

- Number and percent of each category.

- Mean and standard deviation (SD) for numerical data.

- Student $t$ test: for statistically analyzing the difference between the two groups during the follow-up evaluation periods.

\section{Results}

In a total of 80 patients, 30 patients were excluded from the study either due to improperly filling the UPAT or did not follow the treatment and others for not fulfilling the study criteria.

No significant differences were reported between the two groups regarding the duration or difficulty of the surgical procedure 


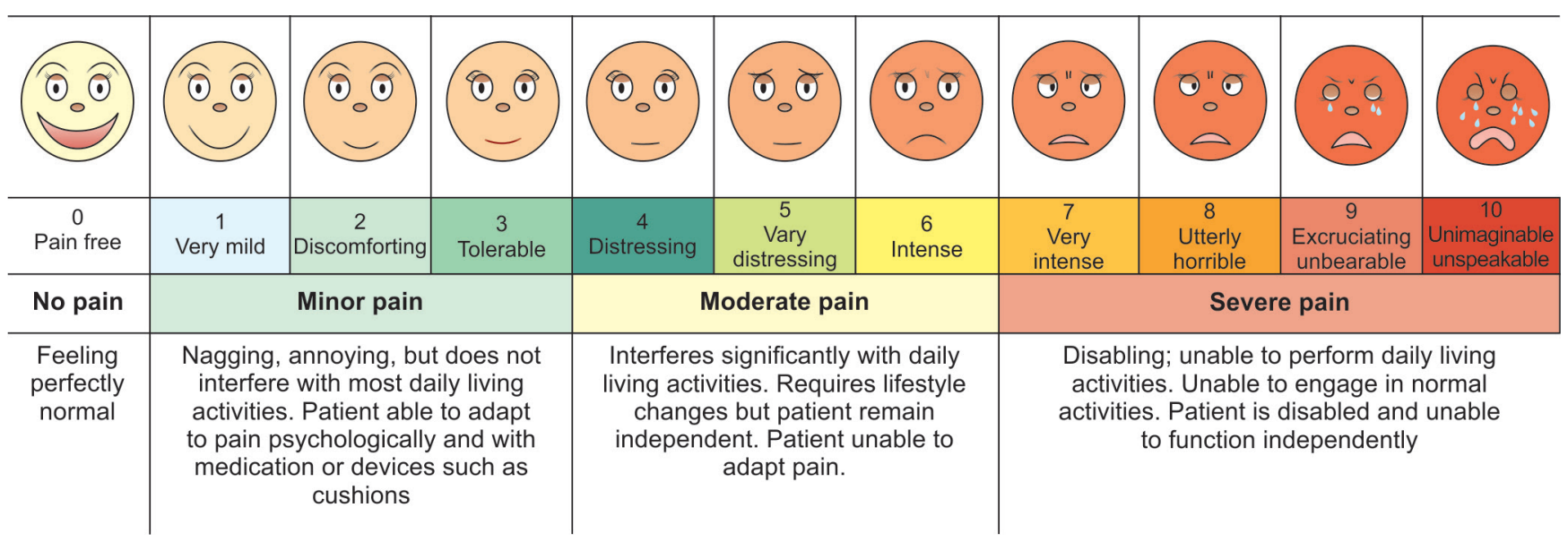

Fig. 3: Universal pain assessment tool

Table 2: The Landry and Turnbull index for wound and soft tissue healing

\begin{tabular}{ll}
\hline Score & Clinical signs \\
\hline Healing index 1: Very poor & Tissue color: $\geq 50 \%$ of gingiva red \\
& Response to palpation: bleeding \\
& Granulation tissue: present \\
& Incision margin: not epithelialized \\
& with loss of epithelium beyond \\
& incision margin \\
& Suppuration: present \\
& Tissue color: $\geq 50 \%$ of gingiva red \\
& Response to palpation: bleeding \\
& Granulation tissue: present \\
Healing index 2: Poor & Incision margin: not epithelialized \\
& with connective tissue exposed \\
& Tissue colorr: $\geq 25 \%$ and $<50 \%$ of \\
& gingiva red \\
& Response to palpation: no bleeding \\
& Granulation tissue: none \\
Healing index 3: Good & Incision margin: no connective tissue \\
& exposed \\
Tissue color: $<25 \%$ of gingiva red \\
Healing index 5: Excellent & Tissue color: all tissues pink \\
& Response to palpation: no bleeding \\
& Granulation tissue: none \\
Incision margin: no connective tissue \\
Incision margin: no connective tissue \\
exposed \\
\hline
\end{tabular}

either in the amount of anesthetic vial used for the surgical procedure (Table 3).

The results show a statistically significant difference between the study and control groups with lower values of pain, swelling, and trismus at $\mathrm{T} 2$ and $\mathrm{T} 3$ of the follow-up period and higher values of the healing index at $\mathrm{T} 1, \mathrm{~T} 2$, and $\mathrm{T} 3$ of the follow-up period among the participants of the study group (Table 4).
Table 3: Demographic and surgical data

\begin{tabular}{lll}
\hline & $\begin{array}{l}\text { Study group } \\
\left(n_{1}=25\right)\end{array}$ & $\begin{array}{l}\text { Control group } \\
\left(n_{2}=25\right)\end{array}$ \\
\hline Mean age in years & $40.1 \pm 7.8$ & $41.4 \pm 7.6$ \\
Surgical difficulty grade: I/II/III/IV* & $6 / 10 / 9 / 0$ & $5 / 9 / 11 / 0$ \\
Mean duration of surgery in min & $28.4 \pm 8.4$ & $30.3 \pm 6.3$ \\
Mean number of anesthetic vials & $2.40 \pm 1.4$ & $2.40 \pm 1.2$ \\
\hline
\end{tabular}

*Surgical difficulty grade by parent scale modified by Garcia Garcia et al.

Pain

Evaluation of pain at T1 of postoperative periods shows a mean score of 0.49 , in the study group and 0.54 in the control group with a $p$ value of 0.669 which is statistically insignificant. On the other hand, at T2 and T3 of postoperative period evaluation shows a mean score of 2.22 and 0.55 in the study group and 3.81 and 1.36 in control group, respectively with a $p$ value $<0.05$ which is statistically significant (Fig. 4).

\section{Edema}

Evaluation of edema at $\mathrm{T} 1$ of postoperative periods shows a mean score of 0.96 , in the study group and 1.78 in the control group with a $p$ value of 0.10 which is statistically insignificant. On the other hand, at T2 and T3 of postoperative period evaluation shows a mean score of 2.64 and 0.00 in the study group and 5.78 and 0.94 in the control group, respectively with a $p$ value $<0.05$ which is statistically significant (Fig. 5).

\section{Trismus}

There was an improvement of the mouth opening in the study group when comparing it to the control group; the difference between the two groups were not significant at T1 while it was significant at $\mathrm{T} 2$ and $\mathrm{T} 3$ with a $p$ value $<0.05$. Most of the participants attained their preoperative interincisal mouth openings at T3 of the postoperative period with superior privilege in the study group in comparison to the control group (Fig. 6).

\section{Wound and Soft Tissue Healing}

A higher proportion of individuals in the study group had better healing index when compared to the control group. This difference was statistically significant at T1, T2 and T3 of postoperative healing with a $p$ value $<0.001$ (Fig. 7). 
660 nm Laser Following Transalveolar Extraction in Female Patients

Table 4: Mean and $p$ values of pain, swelling, trismus, and healing index during the follow-up period

\begin{tabular}{|c|c|c|c|c|c|c|c|c|c|}
\hline & \multicolumn{2}{|c|}{ TO } & \multicolumn{2}{|c|}{$T 1$} & \multicolumn{2}{|c|}{$T 2$} & \multicolumn{2}{|c|}{$T 3$} & \multirow[b]{2}{*}{$p$ value } \\
\hline & Study group & $\begin{array}{l}\text { Control } \\
\text { group }\end{array}$ & $\begin{array}{l}\text { Study } \\
\text { group }\end{array}$ & $\begin{array}{l}\text { Control } \\
\text { group }\end{array}$ & Study group & $\begin{array}{l}\text { Control } \\
\text { group }\end{array}$ & Study group & $\begin{array}{l}\text { Control } \\
\text { group }\end{array}$ & \\
\hline Pain & $0.16 \pm 0.1$ & $0.29 \pm 0.12$ & $0.49 \pm 0.24$ & $0.54 \pm 0.23$ & $2.22 \pm 1.3$ & $3.81 \pm 1.9$ & $0.55 \pm 0.2$ & $1.36 \pm 0.8$ & $\begin{array}{l}0.61 / 0.669 / 0.001^{*} \\
/ 0.04^{*}\end{array}$ \\
\hline Edema & 0.00 & 0.00 & $0.96 \pm 0.45$ & $1.78 \pm 0.93$ & $2.64 \pm 0.54$ & $5.78 \pm 3.54$ & 0.00 & $0.94 \pm 0.63$ & $\begin{array}{l}0.00 / 0.10 /<0.001^{*} \\
/ 0.008^{*}\end{array}$ \\
\hline Trismus & $5.20 \pm 3.4$ & $4.90 \pm 3.1$ & $4.70 \pm 2.75$ & $4.60 \pm 2.9$ & $4.00 \pm 1.97$ & $3.70 \pm 1.62$ & $4.80 \pm 2.34$ & $4.20 \pm 2.64$ & $\begin{array}{l}7.84 / 0.63 /<0.001^{*} \\
/ 0.007^{*}\end{array}$ \\
\hline Healing & 0 & 0 & $3.8 \pm 2.5$ & $2.7 \pm 2.1$ & $4 \pm 1.78$ & $3.6 \pm 1.21$ & $4.8 \pm 2.92$ & $4.0 \pm 2.43$ & $\begin{array}{l}0.00 / 0.002 * / 0.005^{*} \\
/ 0.638\end{array}$ \\
\hline
\end{tabular}

Student's $t$ test, $p<0.05$ (pain/swelling/trismus); $p<0.001$ (healing)

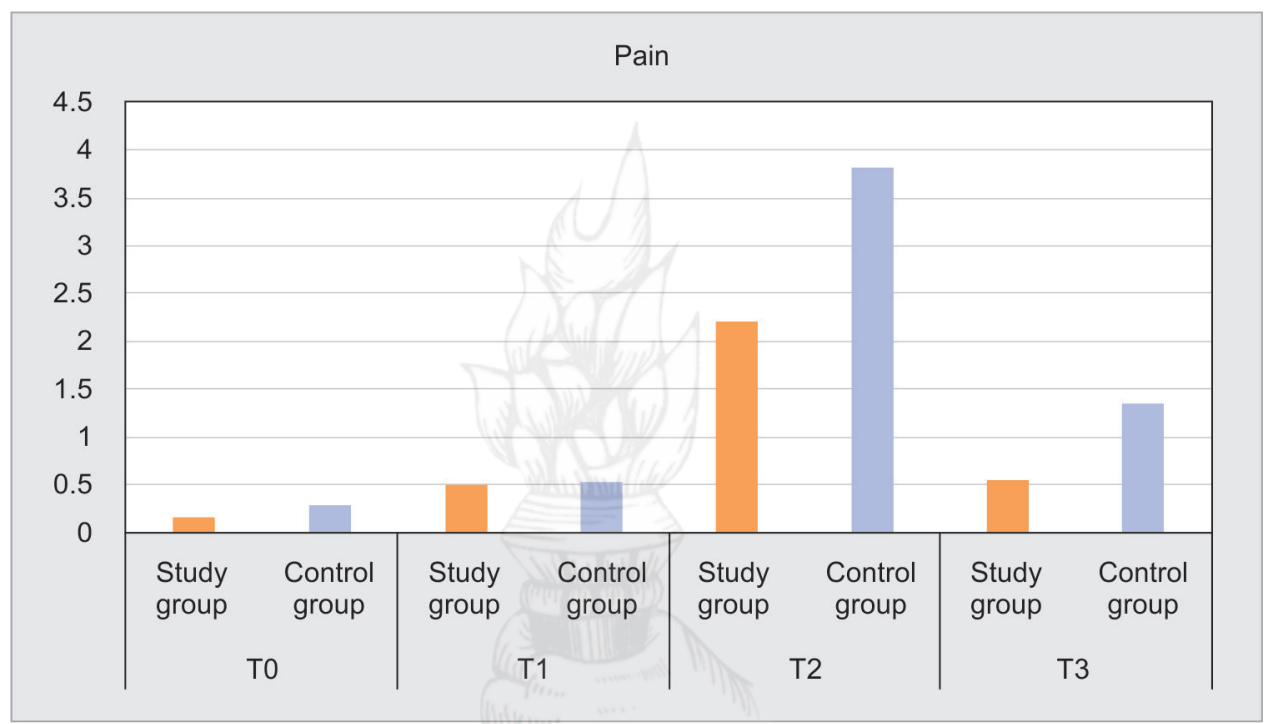

Fig. 4: Difference in pain between two groups during follow-up periods

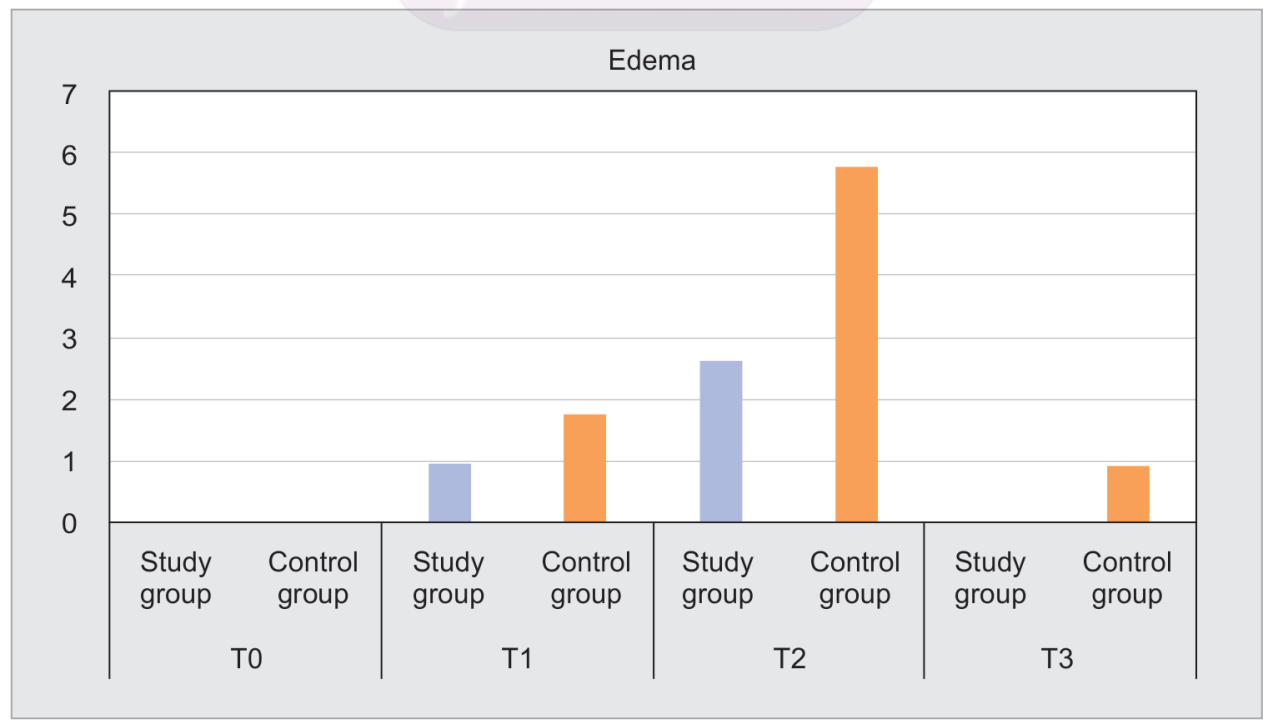

Fig. 5: Difference in edema between two groups during follow-up periods 


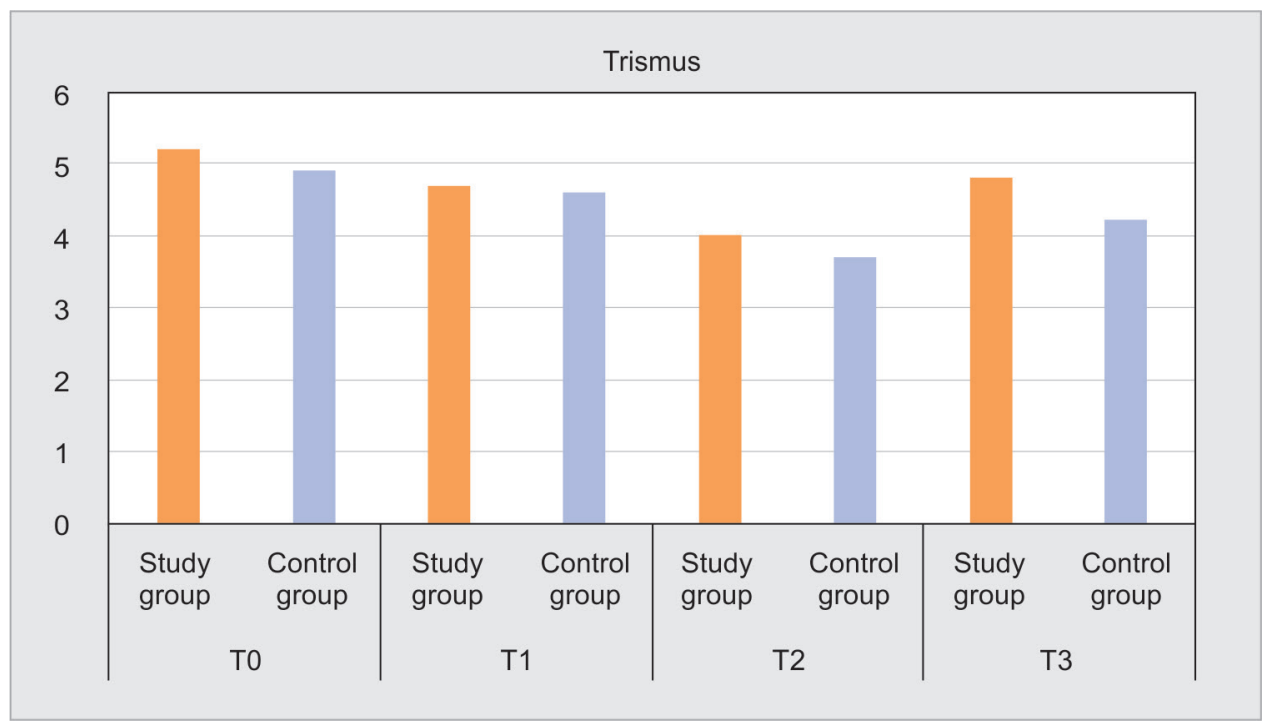

Fig. 6: Difference in trismus between two groups during follow-up periods

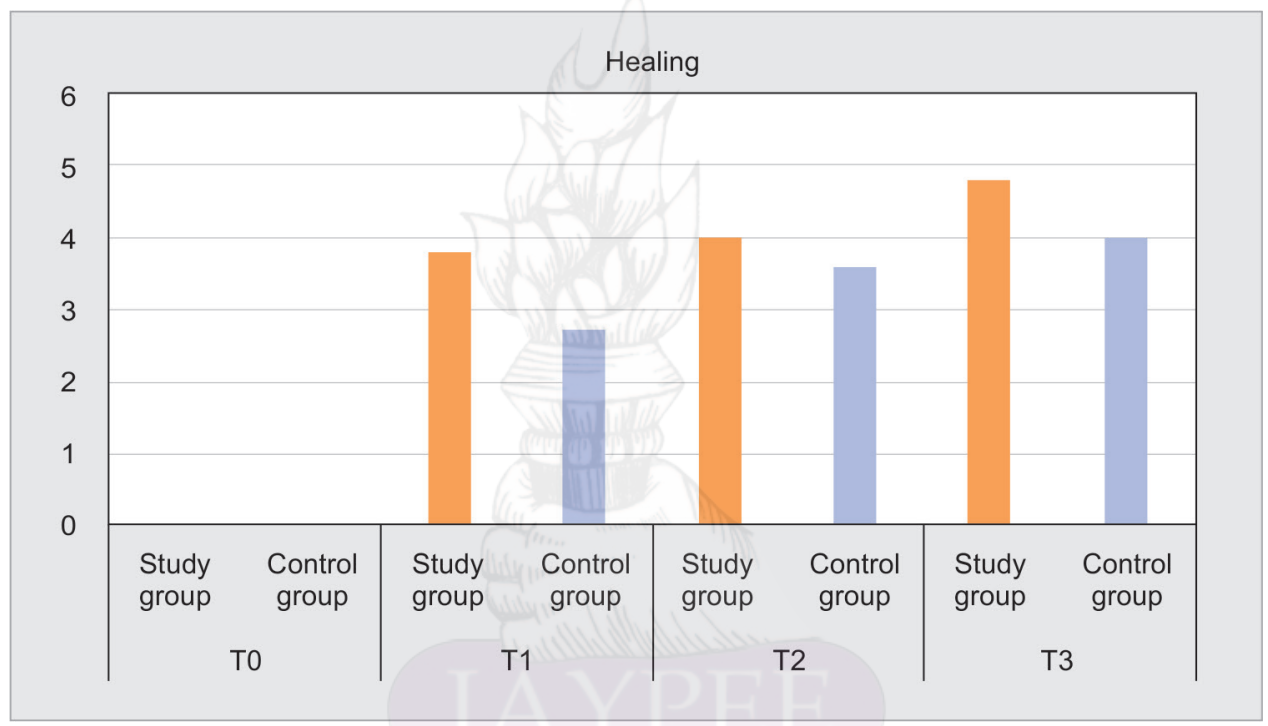

Fig. 7: Difference in healing between two groups during follow-up periods

\section{Discussion}

Extraction of the third molar can be considered as a routine measure that applied daily in oral surgery practice, several complications were advocated third molar surgical extractions. Alveolar osteitis is one of these complications with incidence rate varies between $1 \%$ and $4 \%$ in normal extractions and increased to 5-30\% transalveolar extraction. $^{43}$

One of the risk factors in developing $\mathrm{AO}$ is oral contraceptive (OC) drugs which enhance the fibrinolysis cycle within the extraction socket resulting in disintegration of the clot and consequently the development of AO. ${ }^{43,44}$

The participants in this study were selected to be female patients on oral contraceptive pills. Several investigations proposed that oral contraceptives can be correlated positively with the incidence of $A O .^{13,14,45}$ In our study, although none of the participants in the study or the control groups develop AO, the PBM effect of LLLT resulted in better findings in the study group when comparing to the control group.

Surgical durations were similar between the two groups. No significant difference in the amount of anesthetic used in both groups was reported. To minimize bias all surgical procedures were performed by the same investigator.

Different strategies in the literature were proposed to reduce pain, edema, trismus and the risk of developing $\mathrm{AO}$ that may follow the transalveolar extraction of the lower third molar. ${ }^{15,24}$

Recently, the implementation of LLLT in dentistry is gaining significant concern. Low-level laser therapy reduces the immediate inflammatory reactions and accelerates hard and soft tissue healing with minimizing the risk of developing potential postoperative complications. ${ }^{25}$

Low-level laser therapy is constrained by the difficulties related to the calibration of the laser type, its wavelength output power, mode and time of the application, and the procedure utilized. ${ }^{19,46}$ 
In our study group, the laser beam was administrated precisely over the surgical site for 60 seconds with constant irradiation. The MultiTip $8 \mathrm{~mm}$ was set at a distance of $1 \mathrm{~cm}$ in noncontact mode from the tissue surface. The power was adjusted to $25 \mathrm{~mW}$, with a $660 \mathrm{~nm}$ wavelength. In 2005, Marković and coworker propose using energy output $4 \mathrm{~J} / \mathrm{cm}^{2}$ with a constant power density of $50 \mathrm{~mW}$, wavelength $637 \mathrm{~nm}$ to assess the effectiveness of dexamethasone and low-power laser in minimizing edema after third molar surgery. ${ }^{5}$

On the other hand, Landucci et al. in 2015 propose using one dosage of $7.5 \mathrm{~J} / \mathrm{cm}^{2}$ at $10 \mathrm{~mW}$, with an infrared $780 \mathrm{~nm}$ wavelength to assess the effectiveness of a single dose of LLLT in decreasing the postsurgical complications correlated to surgical extraction of the third molar. ${ }^{47}$

In this study the values of pain, edema, and trismus were significantly lower in the study group compared to the control group $(p<0.05)$ at T2 and T3 of the follow-up periods.

Several studies did not succeed to record any favorable effects of LLLT in decreasing pain and edema associated with mandibular third molar extraction. Also, Taube et al. not able to report an advantageous result of using a single dose of LLLT in minimizing the postoperative pain following surgical extraction of the third molar. $^{44,46}$

On the other hand, Roynesdal et al. ${ }^{48}$ reported lower values of pain, edema, and trismus at 9 hours after applying LLLT following third molar extraction surgery. Unfortunately, they were not able to confirm their findings statistically which may be attributed to the low irradiation dose they apply and short assessment period.

The impact of LLLT on severe pain following trauma proposed to be attributed to a decrease in edema, hemorrhage, neutrophil infiltration, and enzyme. ${ }^{49}$ Saber et al. reported a reduction of pain at 48 hours postoperatively following the application of LLLT; however, no significant effects on the duration of pain were observed 7 days postoperatively. ${ }^{50}$ Wathier et al. also reported a statistically significant reduction of pain at $1-5$ days of postoperatively following the application of LLLT. ${ }^{51}$

On the other hand, Aras and Güngörmüş, ${ }^{52}$ and Carrillo et al. ${ }^{40}$ observed a significant reduction in pain and trismus only after 7 postoperative days following an administration of intraoral LLLT. Also, Roynesdal et al. ${ }^{48}$ and Fernando et al., ${ }^{53}$ reported that no clinical efficacious of LLLT was observed on lowering the postoperative complications associated with third molar surgery.

In 2015, Landucci et al. were evaluating the efficacy of a single dose of LLLT in reducing pain, edema, and trismus following third molar extraction surgery, and they reported that using $780 \mathrm{~nm}$ wavelength LLLT will reduce pain, trismus, and edema because it penetrates deep into tissues. ${ }^{47}$

In our study, the healing index in the study group was superior then in the control group and the difference was statistically significant at $\mathrm{T} 1, \mathrm{~T} 2$, and $\mathrm{T} 3$; of the postoperative period. ${ }^{54,55}$ This may be related to the fact that LLLT is not only capable to reduce pain and inflammation, but also can increase the rate and quality of wound healing through multiple processes involving increased proliferation of fibroblasts, ${ }^{56}$ promoted epithelization, ${ }^{57}$ enhanced organization and maturation of collagen fibers ${ }^{58}$ and increased matrix synthesis and angiogenesis. ${ }^{54}$

The clinical action of LLLT can be linked to the expression of antiapoptosis and prosurvival genes responsive to nuclear factor kappa B (NF-kB). Low-level laser therapy can also promote mitochondrial respiration and stimulates redox-sensitive NF-KB signaling via the production of reactive oxygen species (ROS). ${ }^{59}$
Moreover, the effect of LLLT on cell membranes trigger the cellular response that induces multiple biochemical reactions and modifies the physiological processes in addition to enhance and promote secondary or indirect actions, and increase blood flow and lymphatic drainage result in the acceleration of the healing process. $^{31}$

\section{Conclusion}

Although both group showed a reduction of postoperative complications following transalveolar extraction of the mandibular third molar, but using single-dose LLLT with a wavelength $660 \mathrm{~nm}$, demonstrated a reduction of postoperative complication, and promoting soft and hard tissue healing when compared to the control group, that resulted in more patient satisfaction toward the dental service provided to them.

\section{Consent}

All authors declare that written informed consent was obtained from the patient prior conducting this research.

\section{Ethical Approval}

All authors hereby declare that all experiments have been examined and approved by the appropriate ethics committee (Code\#: ST/50/2018) and have therefore been performed in accordance with the ethical standards laid down in the 1964 declaration of Helsinki.

\section{References}

1. Sisk AL, Hammer WB, Shelton DW, et al. Complications following removal of impacted third molars: the role of the experience of the surgeon. J Oral Maxillofac Surg 1986;44(11):855-859. DOI: 10.1016/0278-2391(86)90221-1.

2. Woldenberg Y, Gatot I, Bodner L. latrogenic mandibular fracture associated with third molar removal. Can it be prevented? Med Oral Patol Oral Cir Bucal 2007;12(1):E70-E72.

3. Kunkel M, Morbach T, Kleis W, et al. Third molar complications requiring hospitalization. Oral Surg Oral Med Oral Pathol Oral Radiol Endod 2006;102(3):300-306. DOI: 10.1016/j.tripleo.2005.09.010.

4. Barbosa-Rebellato NL, Thome A, Costa-Maciel C, et al. Factors associated with complications of removal of third molars: a transversal study. Med Oral Patol Oral Cir Bucal 2011;16(3):e376-e380. DOI: 10.4317/medoral.16.e376.

5. Marković AB, Todorović L. Postoperative analgesia after lower third molar surgery: contribution of the use of long-acting local anesthetics, low-power laser, and diclofenac. Oral Surg Oral Med Oral Pathol Oral Radiol Endod 2006;102(5):e4-e8. DOI: 10.1016/ j.tripleo.2006.02.024.

6. Lago-Méndez L, Diniz-Freitas M, Senra-Rivera C, et al. Relationships between surgical difficulty and postoperative pain in lower third molar extractions. J Oral Maxillofac Surg 2007;65(5):979-983. DOI: 10.1016/j.joms.2006.06.281.

7. Darawade DA, Kumar S, Mehta R, et al. In search of a better option: dexamethasone versus methylprednisolone in third molar impaction surgery. J Int Oral Health 2014;6(6):14-17.

8. Ayaz H. Post-operative complications associated with impacted mandibular third molar removal. PODJ 2012;32(3):4.

9. Miloro M, Ghali GE, Larsen P, et al. Peterson's principles of oral and maxillofacial surgery. USA: PMPH; 2004. p. 760.

10. Vezeau PJ. Dental extraction wound management: medicating postextraction sockets. J Oral Maxillofac Surg 2000;58(5):531-537. DOI: 10.1016/s0278-2391(00)90016-8.

11. Schow SR. Evaluation of postoperative localized osteitis in mandibular third molar surgery. Oral Surg Oral Med Oral Pathol 1974;38(3): 352-358. DOI: 10.1016/0030-4220(74)90360-0. 
12. Sweet JB, Butler DP. Increased incidence of postoperative localized osteitis in mandibular third molar surgery associated with patients using oral contraceptives. Am J Obstet Gynecol 1977;127(5):518-519. DOI: 10.1016/0002-9378(77)90446-x.

13. Cohen ME, Simecek JW. Effects of gender-related factors on the incidence of localized alveolar osteitis. Oral Surg Oral Med Oral Pathol Oral Radiol Endod 1995;79(4):416-422. DOI: 10.1016/s10792104(05)80120-9.

14. Ygge J, Brody S, Korsan-Bengtsen K, et al. Changes in blood coagulation and fibrinolysis in women receiving oral contraceptives: comparison between treated and untreated women in a longitudinal study. Am J Obstet Gynecol 1969;104(1):87-98. DOI: 10.1016/s00029378(16)34145-x.

15. Dubois DD, Pizer ME, Chinnis RJ. Comparison of primary and secondary closure techniques after removal of impacted mandibular third molars. J Oral Maxillofac Surg 1982;40(10):631-634. DOI: 10.1016/0278-2391(82)90111-2.

16. Holland CS, Hindle MO. The influence of closure or dressing of third molar sockets on post-operative swelling and pain. $\mathrm{Br} J$ Oral Maxillofac Surg 1984;22(1):65-71. DOI: 10.1016/0266-4356(84)90011-1.

17. Seymour RA, Meechan JG, Blair GS. An investigation into postoperative pain after third molar surgery under local analgesia. Br J Oral Maxillofac Surg 1985;23(6):410-418. DOI: 10.1016/02664356(85)90025-7.

18. Capuzzi P, Montebugnoli L, Vaccaro MA. Extraction of impacted third molars: a longitudinal prospective study on factors that affect postoperative recovery. Oral Surg Oral Med Oral Pathol 1994;77(4):341-343. DOI: 10.1016/0030-4220(94)90194-5.

19. Markovic A, Todorovic LJ. Effectiveness of dexamethasone and lowpower laser in minimizing oedema after third molar surgery: a clinical trial. Int J Oral Maxillofac Surg 2007;36(3):226-229. DOI: 10.1016/ j.ijom.2006.10.006.

20. Salem S, Saad I. Evaluation of blood banked fibrin glue versus blood banked platelet glue as a local hemosatic agent and a healing promoter in patients with acute leukemia undergoing tooth extraction. Br J Med Med Res 2017;21(7):1-13.

21. Chakravarthi S. Platelet rich fibrin in the management of established dry socket. J Korean Assoc Oral Maxillofac Surg 2017;43(3):160-165. DOI: 10.5125/jkaoms.2017.43.3.160.

22. Hermesch CB, Hilton TJ, Biesbrock AR, et al. Perioperative use of $0.12 \%$ chlorhexidine gluconate for the prevention of alveolar osteitis: efficacy and risk factor analysis. Oral Surg Oral Med Oral Pathol Oral Radiol Endod 1998;85(4):381-387. DOI: 10.1016/s1079-2104(98) 90061-0.

23. Sekhar $\mathrm{CH}$, Narayanan V, Baig MF. Role of antimicrobials in third molar surgery: prospective, double blind, randomized, placebo-controlled clinical study. Br J Oral Maxillofac Surg 2001;39(2):134-137. DOI: 10.1054/bjom.2000.0557.

24. Sortino F, Messina G, Pulvirenti G. Evaluation of postoperative mucosa and skin temperature after surgery for impacted third molar. Minerva Stomatol 2003;52(7-8):393-399.

25. Walsh LJ. The current status of low level laser therapy in dentistry, part 1. soft tissue applications. Aust Dent J 1997;42(4):247-254. DOI: 10.1111/j.1834-7819.1997.tb00129.x.

26. Tafur J, Mills PJ. Low-intensity light therapy: exploring the role of redox mechanisms. Photomed Laser Surg 2008;26(4):323-328. DOI: 10.1089/pho.2007.2184.

27. Karu T. Low power laser therapy. Biomedical photonics handbook. CRC Press, Taylor Francis Group; 2003. p. 48.

28. Moore KC, Hira N, Broome IJ, et al. The effect of infra-red diode laser irradiation on the duration and severity of postoperative pain: a double blind trial. Laser Ther 1992;4(4):145-149.

29. Kawasaki K, Shimizu N. Effects of low-energy laser irradiation on bone remodeling during experimental tooth movement in rats. Lasers Surg Med 2000;26(3):282-291. DOI: 10.1002/(sici)10969101(2000)26:3<282::aid-Ism6>3.0.co;2-x.

30. Sobouti F, Khatami M, Heydari $M$, et al. The role of low-level laser in periodontal surgeries. J Lasers Med Sci 2015;6(2):45-50.
31. Lievens PC. The effect of a combined $\mathrm{HeNe}$ and i.r. laser treatment on the regeneration of the lymphatic system during the process of wound healing. Lasers Med Sci 1991;6(2):193-199.

32. Ozen T, Orhan K, Gorur I, et al. Efficacy of low level laser therapy on neurosensory recovery after injury to the inferior alveolar nerve. Head Face Med 2006;2:3. DOI: 10.1186/1746-160X-2-3.

33. Leung YY, Fung PP-L, Cheung LK. Treatment modalities of neurosensory deficit after lower third molar surgery: a systematic review. J Oral Maxillofac Surg 2012;70(4):768-778. DOI: 10.1016/ j.joms.2011.08.032.

34. lijima K, Shimoyama N, Shimoyama M, et al. Effect of low-power He-Ne laser on deformability of stored human erythrocytes. J Clin Laser Med Surg 1993;11(4):185-189. DOI: 10.1089/clm.1993. 11.185 .

35. Passarella S, Casamassima E, Molinari S, et al. Increase of proton electrochemical potential and ATP synthesis in rat liver mitochondria irradiated in vitro by helium-neon laser. FEBS Lett 1984;175(1):95-99. DOI: 10.1016/0014-5793(84)80577-3.

36. Oltra-Arimon D, España-Tost AJ, Berini-Aytés $L$, et al. Aplicaciones del láser de baja potencia en Odontología. RCOE 2004;9(5):517-524.

37. Navratil L, Kymplova J. Contraindications in noninvasive laser therapy: truth and fiction. J Clin Laser Med Surg 2002;20(6):341-343. DOI: 10.1089/104454702320901134.

38. Garcia Garcia A, Sampedro FG, Rey JG, et al. Trismus and pain after removal of impacted lower third molars. J Oral Maxillofac Surg 1997;55(11):1223-1226. DOI: 10.1016/s0278-2391(97)90172-5.

39. Gupta R, Sharma K, Dhiman UK. Effect of a combination of oral midazolam and low-dose ketamine on anxiety, pain, swelling, and comfort during and after surgical extractions of mandibular third molars. Indian J Dent Res 2012;23(2):295-296. DOI: 10.4103/09709290.100460

40. Carrillo JS, Calatayud J, Manso FJ, et al. A randomized doubleblind clinical trial on the effectiveness of helium-neon laser in the prevention of pain, swelling and trismus after removal of impacted third molars. Int Dent J 1990;40(1):31-36.

41. Laureano Filho JR, Maurette PE, Allais M, et al. Clinical comparative study of the effectiveness of two dosages of Dexamethasone to control postoperative swelling, trismus and pain after the surgical extraction of mandibular impacted third molars. Med Oral Patol Oral Cir Bucal 2008;13(2):E129-E132.

42. Landry RG, Turnbull RS, Howley T. Effectiveness of benzydamyne $\mathrm{HCl}$ in the treatment of periodontal post-surgical patients. Res Clin Forum 1988;10:105.

43. Osborn TP, Frederickson G, Small IA, et al. A prospective study of complications related to mandibular third molar surgery. J Oral Maxillofac Surg 1985;43(10):767-769. DOI: 10.1016/02782391(85)90331-3.

44. Eshghpour M, Rezaei NM, Nejat A. Effect of menstrual cycle on frequency of alveolar osteitis in women undergoing surgical removal of mandibular third molar: a single-blind randomized clinical trial. J Oral Maxillofac Surg 2013;71(9):1484-1489. DOI: 10.1016/ j.joms.2013.05.004.

45. Catellani JE, Harvey S, Erickson SH, et al. Effect of oral contraceptive cycle on dry socket (localized alveolar osteitis). J Am Dent Assoc 1980;101(5):777-780. DOI: 10.14219/jada.archive.1980.0420.

46. Taube S, Piironen J, Ylipaavalniemi P. Helium-neon laser therapy in the prevention of postoperative swelling and pain after wisdom tooth extraction. Proc Finn Dent Soc 1990;8:23-27.

47. Landucci A, Wosny AC, Uetanabaro LC, et al. Efficacy of a single dose of low-level laser therapy in reducing pain, swelling, and trismus following third molar extraction surgery. Int J Oral Maxillofac Surg 2016;45(3):392-398. DOI: 10.1016/j.ijom.2015.10.023.

48. Roynesdal AK, Björnland T, Barkvoll P, et al. The effect of soft-laser application on postoperative pain and swelling: a double-blind, crossover study. Int J Oral Maxillofac Surg 1993;22(4):242-245. DOI: 10.1016/s0901-5027(05)80646-0.

49. Bjordal JM, Johnson Ml, Iversen $\mathrm{V}$, et al. Low-level laser therapy in acute pain: a systematic review of possible mechanisms of action and 
clinical effects in randomized placebo-controlled trials. Photomed Laser Surg 2006;24(2):158-168. DOI: 10.1089/pho.2006.24.158.

50. Saber K, Chiniforush N, Shahabi S. The effect of low level laser therapy on pain reduction after third molar surgery. Minerva Stomatol 2012;61(7-8):319-322.

51. Wathier J, Contar CMM, Alanis LRA, et al. Avaliação da efetividade do laser de baixa potência na redução da dor pós-operatória em cirurgia de terceiros molares inferiores inclusos. Odonto 2011;19(38):131-138.

52. Aras $M H$, Güngörmüş $M$. The effect of low-level laser therapy on trismus and facial swelling following surgical extraction of a lower third molar. Photomed Laser Surg 2009;27(1):21-24. DOI: 10.1089/ pho.2008.2258.

53. Fernando S, Hill CM, Walker R. A randomised double blind comparative study of low level laser therapy following surgical extraction of lower third molar teeth. Br J Oral Maxillofac Surg 1993;31(3):170-172. DOI: 10.1016/0266-4356(93)90118-g.

54. Viegas VN, Abreu MER, Viezzer C, et al. Effect of low-level laser therapy on inflammatory reactions during wound healing: comparison with meloxicam. Photomed Laser Surg 2007;25(6):467-473. DOI: 10.1089/ pho.2007.1098.
55. Maiya GA, Kumar P, Rao L. Effect of low intensity helium-neon (He-Ne) laser irradiation on diabetic wound healing dynamics. Photomed Laser Surg 2005;23(2):187-190. DOI: 10.1089/pho.2005. 23.187.

56. Khadra M, Lyngstadaas SP, Haanæs HR, et al. Determining optimal dose of laser therapy for attachment and proliferation of human oral fibroblasts cultured on titanium implant material. J Biomed Mater Res A 2005;73(1):55-62. DOI: 10.1002/jbm.a.30270.

57. Ozcelik O, Haytac MC, Kunin A, et al. Improved wound healing by low-level laser irradiation after gingivectomy operations: a controlled clinical pilot study. J Clin Periodontol 2008;35(3):250-254. DOI: 10.1111/j.1600-051X.2007.01194.x.

58. Medrado AP, Soares AP, Santos ET, et al. Influence of laser photobiomodulation upon connective tissue remodeling during wound healing. J Photochem Photobiol B 2008;92(3):144-152. DOI: 10.1016/j.jphotobiol.2008.05.008.

59. Chen AC-H, Arany PR, Huang Y-Y, et al. Low-level laser therapy activates NF-kB via generation of reactive oxygen species in mouse embryonic fibroblasts. PLoS One 2011;6(7):e22453. DOI: 10.1371/ journal.pone.0022453. 